\title{
Treatment of Moderate to Severe Alzheimer's Disease: Rationale and Trial Design
}

\author{
Nathan Herrmann
}

\begin{abstract}
Moderate to severe Alzheimer's disease (AD) is characterized by increasing cognitive, functional, and behavioural dysfunction that results in increased caregiver burden and, eventually, complete dependence. Despite its significance as a societal health problem, there are few treatment trials of cognitive enhancers or disease modifying agents for this stage of illness. Studies suggest the cholinesterase inhibitors, especially donepezil, may provide benefit. Several studies provide support for the use of the NMDA receptor antagonist memantine as monotherapy or added to a cholinesterase inhibitor for moderate to severe AD. While there are no published guidelines for the treatment of moderate to severe $\mathrm{AD}$, these studies do provide guidance for recommendations for study design and outcome measures. Such studies are urgently needed.
\end{abstract}

RÉSUMÉ: Traitement de la maladie d'Alzheimer de modérée à sévère : justification et plan d'essais. La maladie d'Alzheimer de modérée à sévère est caractérisée par une dysfonction cognitive, fonctionnelle et comportementale progressive qui engendre un fardeau croissant pour les soignants et une dépendance complète éventuelle. En dépit de son importance comme problème de santé au niveau sociétal, il existe peu d'essais thérapeutiques portant sur des stimulateurs cognitifs ou des agents modificateurs de la maladie à ce stade de la maladie. Les études suggèrent que les inhibiteurs de la cholinestérase, spécialement le donépézil sont bénéfiques. Selon plusieurs études, l'utilisation de la mémantine, un antagoniste du récepteur NMDA, en monothérapie ou en association à un inhibiteur de la cholinestérase serait bénéfique dans la MA de modérée à sévère. Bien qu'il n'y ait pas de lignes directrices publiées concernant le traitement de la MA de modérée à sévère, ces études peuvent servir de guide pour formuler des recommandations sur le plan d'étude et les critères d'évaluation. Il est urgent de procéder à de telles études.

Can. J. Neurol. Sci. 2007; 34: Suppl. 1 - S103-108

\section{Rationale for Treatment Studies}

Alzheimer's disease (AD) is a neurodegenerative disorder characterized by progressive cognitive and functional impairment and behavioural and psychological symptoms (BPSD). As the disease progresses, the patient becomes more functionally impaired with total dependence on caregivers being a hallmark of the more severe stages. The Canadian Study of Health and Aging (CSHA) estimated that $50 \%$ of individuals diagnosed with $\mathrm{AD}$ were already in the moderate to severe stages, while almost $90 \%$ of patients in long-term care facilities were moderate to severe. ${ }^{1}$ As dependence on the caregiver increases, the degree of caregiver burden and stress increases, leading to an increased risk of institutionalization for the patient and increased medical and psychological morbidity for the caregiver. ${ }^{2}$ Furthermore, the dependence leads to an increased demand on caregiver time, a major contributor to indirect care costs, while institutionalization comprises the most significant driver of direct costs for dementia care. The CSHA estimated that as a result of these factors, the cost of care for $\mathrm{AD}$ patients rises dramatically for mild to moderate to severe illness. ${ }^{3}$ The Kungsholmen project noted that the severe stages of dementia account for $70-80 \%$ of the total costs. ${ }^{4}$ Due to its prevalence, associated disability, contribution to caregiver burden, and stress,

From the Department of Psychiatry, Division of Geriatric Psychiatry, Faculty of Medicine, University of Toronto, Sunnybrook \& Women's College Health Sciences Centre, Toronto, ON, Canada.

Received October 7, 2005. Accepted in final form February 21, 2006. Reprint requests to: Nathan Herrmann, Department of Psychiatry, Division of Geriatric Psychiatry, Faculty of Medicine, University of Toronto, Sunnybrook \& Women's College Health Sciences Centre, Toronto, Ontario, M4N 3M5, Canada. 
as well as direct and indirect costs, moderate to severe AD clearly represents an important societal health problem. This alone provides a strong rationale for the study of therapeutic interventions.

There are emerging data that suggest there are differences between mild and moderate to severe AD in neuropathology and neurochemistry, which may have important implications for pharmacotherapy. Stage-specific changes in amyloid plaque and neurofibrillary tangle burden have been documented, ${ }^{5}$ as well as changes in neurotransmitters, such as catecholamines, ${ }^{6,7} \mathrm{GABA},{ }^{8}$ and glutamate. ${ }^{9}$ For example, in the cholinergic system (the beststudied of the neurotransmitter systems in AD) cholinergic markers, such as choline acetyltransference (ChAT), do not decline significantly until later stages of $\mathrm{AD}$, while milder stages are characterized by relatively preserved ChAT. ${ }^{10}$ This type of data has led to the hypothesis that cholinesterase inhibitors may be more effective for moderate to severe $\mathrm{AD}$ than milder disease. ${ }^{11}$ It also suggests that pharmacological agents studied in mild AD may be more or less effective in moderate to severe AD.

Unfortunately, at the present time, there are no clinical practice guidelines (CPGs) specific for moderate to severe AD. The cholinesterase inhibitors (ChEIs) are indicated for mild to moderate $\mathrm{AD}$, but where provincial formularies reimburse their costs, payment is contingent on patients scoring between 10-26 on a Mini-Mental State Examination (MMSE). ${ }^{12}$ Memantine has only recently received conditional approval for the treatment of moderate to severe AD in Canada. While many pharmacological treatment trials for BPSD have focused on moderate to severe AD patients, ${ }^{13}$ there are very few trials on cognitive enhancers or disease-modifying agents for this stage of illness.

Table: Randomized Trials for Moderate-Severe AD

\begin{tabular}{|c|c|c|c|c|c|c|c|}
\hline Study & Drugs & $\mathrm{N}$ & $\begin{array}{l}\text { Inclusion } \\
\text { Criteria }\end{array}$ & $\begin{array}{l}\text { Baseline } \\
\text { MMSE }\end{array}$ & $\begin{array}{c}\text { Primary outcome } \\
\text { measure }(\mathrm{s})\end{array}$ & $\begin{array}{c}\text { Secondary outcome } \\
\text { measures }\end{array}$ & Findings \\
\hline $\begin{array}{l}\text { Feldman et al } \\
2001^{11}\end{array}$ & $\begin{array}{l}\text { donepezil } \\
10 \mathrm{mg} \text { vs } \\
\text { placebo }\end{array}$ & 290 & $\begin{array}{l}\text { - MMSE 5-17 } \\
\text { - FAST } \leq 6\end{array}$ & $\approx 12$ & CIBIC+ & $\begin{array}{l}\text { MMSE, SIB, } \\
\text { DAD, IADL, } \\
\text { PSMS, NPI, } \\
\text { FRS, CSS, } \\
\text { HRQLCQ, } \\
\text { CUSTQ }\end{array}$ & $\begin{array}{l}\text { donepezil>placebo on } \\
\text { CIBIC+ }\end{array}$ \\
\hline $\begin{array}{l}\text { Tariot et al } \\
2001^{27}\end{array}$ & $\begin{array}{l}\text { donepezil } 10 \mathrm{mg} \\
\text { vs placebo }\end{array}$ & 208 & $\begin{array}{l}\text { - MMSE 5-26 } \\
\text { - NPI at least } 3-4 \\
\text { for frequency on at } \\
\text { least } 1 \text { symptom }\end{array}$ & $\approx 14$ & NPI-NH & $\begin{array}{l}\text { MMSE } \\
\text { CDR-SB } \\
\text { PSMS }\end{array}$ & $\begin{array}{l}\text { donepezil= placebo on NPI- } \\
\text { NH. } \\
\text { donepezil>placebo on some } \\
\text { secondary measures }\end{array}$ \\
\hline $\begin{array}{l}\text { Winblad and } \\
\text { Poritis } 1999^{29}\end{array}$ & $\begin{array}{l}\text { memantine } 10 \\
\text { mg day vs } \\
\text { placebo }\end{array}$ & 166 & $\begin{array}{l}\text { - GDS 5-7 } \\
\text { - MMSE<10 }\end{array}$ & $\approx 6$ & $\begin{array}{l}\text { CGI-C } \\
\text { BGP }\end{array}$ & Ferm's-D & $\begin{array}{l}\text { memantine }>\text { placebo on } \\
\text { primary outcome measures }\end{array}$ \\
\hline $\begin{array}{l}\text { Reisberg et al } \\
2003^{34}\end{array}$ & $\begin{array}{l}\text { memantine } 20 \\
\text { mg BID vs } \\
\text { placebo }\end{array}$ & 252 & $\begin{array}{l}\text { - MMSE } \\
\text { 3-14 } \\
\text { - GDS } 5 \text { or } 6\end{array}$ & $\approx 8$ & $\begin{array}{l}\mathrm{CIBIC}+ \\
\mathrm{ADCS} / \mathrm{ADL}_{\mathrm{SEV}}\end{array}$ & $\begin{array}{l}\text { SIB, MMSE } \\
\text { GDS, FAST } \\
\text { NPI, RUD }\end{array}$ & $\begin{array}{l}\text { memantine }>\text { placebo on } \\
\text { CIBIC }+(p=0.06) \\
\text { ADCS } / A D L_{S E V}(p=0.02) \text { and } \\
\text { SIB }(p<0.001)\end{array}$ \\
\hline $\begin{array}{l}\text { Tariot et al } \\
2004^{38}\end{array}$ & $\begin{array}{l}\text { memantine } 20 \\
\text { mg BID + } \\
\text { donepezil vs } \\
\text { placebo + } \\
\text { donepezil }\end{array}$ & 404 & $\begin{array}{l}- \text { MMSE } \\
5-14\end{array}$ & $\approx 10$ & $\begin{array}{l}\text { SIB } \\
\text { ADCS/ADL }\end{array}$ & $\begin{array}{l}\text { CIBIC, NPI } \\
\text { BGP, FAST }\end{array}$ & $\begin{array}{l}\text { memantine }+ \text { donepezil } \\
>\text { placebo }+ \text { donepezil on all } \\
\text { measures }\end{array}$ \\
\hline $\begin{array}{l}\text { Sano et al } \\
1999^{39}\end{array}$ & $\begin{array}{l}\text { Vitamin E } 1000 \\
\text { IU } \\
\text { BID vs } \\
\text { selegiline } 10 \mathrm{mg} \\
\text { vs combination } \\
\text { vs placebo }\end{array}$ & 341 & - CDR 2 & $\approx$ & $\begin{array}{l}\text { Death, or } \\
\text { institutionalization } \\
\text { or loss of } 2 / 3 \text { key } \\
\text { ADLs or CDR } 3\end{array}$ & $\begin{array}{l}\text { ADASCog, } \\
\text { MMSE, BDS, } \\
\text { DS, BRS, } \\
\text { UPDRS }\end{array}$ & $\begin{array}{l}\text { - No differences between } \\
\text { treatments } \\
\text { - when adjusted for baseline } \\
\text { MMSE selegiline, vitamin E, } \\
\text { and combination>placebo }\end{array}$ \\
\hline
\end{tabular}

MMSE = Mini Mental State Examination; FAST = Functional Assessment Staging; CIBIC $+=$ Clinician's Interview Based Impression of Change plus Caregiver Input; SIB = Severe Impairment Battery; DAD = Disability Assessment for Dementia; IADL = Instrumental Activities of Daily Living PSMS = Progressive Self-Maintenance Scale; NPI = Neuropsychiatric Inventory; FRS = Functional Rating Scale; CSS = Caregiver Stress Scale; HRQLCQ = Health-Related Quality of Life of Caregiver Questionnaire; CUSTQ = Canadian Utilization of Services Tracking Questionnaire; NPI$\mathrm{NH}=$ Neuropsychiatric Inventory Nursing Home Version; CDR-SB = Clinical Dementia Rating Scale Sum of Boxes; GDS = Global Deterioration Scale; CGI-C = Clinician's Global Impression of Change; BGP = Behavioral Rating Scale for Geriatric Patients; ADCS/ADLSEV = Alzheimer's Disease Cooperative Study Activities of Daily Living-Severe; ADASCog = Alzheimer's Disease Assessment Scale Cognitive Subscale; BDS = Blessed Dementia Scale; DS = Dependence Scale; BRS = Behavior Rating Scale for Dementia; UPDRS = Unified Parkinson's Disease Rating Scale 


\section{Methods}

Despite the significance of moderate to severe AD, and evidence that treatments for milder illness cannot necessarily be assumed to be effective for more severe disease, there is a dearth of studies to date to inform treatment guidelines. In order to recommend appropriate trial designs for moderate to severe $\mathrm{AD}$, a literature search was conducted with Medline using keywords: Alzheimer's disease, moderate, severe, and therapy. A review of the study methodologies highlighted the challenges associated with this area of research and provided guidelines for trial design and choice of instruments, which follows.

\section{RESUlts}

\section{Cholinesterase Inhibitors}

The pivotal ChEI studies included subjects with mild to moderate AD, generally with MMSE scores in the range of 10$26 .{ }^{14}$ While there are several post-hoc analyses of rivastigmineand galantamine-treated patients from these trials, who at baseline scored near the bottom of this range (e.g., MMSE $\leq 14),{ }^{15,16}$ only two studies with donepezil have been published using inclusion criteria specifically focused on moderate to severe $\mathrm{AD}$ (Table). In a 24-week randomized, double-blind, placebo-controlled, parallel group trial of donepezil, Feldman et al. studied $290 \mathrm{AD}$ patients with moderate to severe AD. ${ }^{11}$ Inclusion criteria included MMSE scores of 5-17 and a Functional Assessment Staging Test (FAST) score of $\leq 6 .{ }^{17}$ This resulted in groups with average baseline MMSEs of approximately 12 . The primary efficacy measure was the Clinician Interview-based Impression of Change with Caregiver Input (CIBIC+).$^{18}$ Secondary measures included: the MMSE and the Severe Impairment Battery (SIB) as cognitive assessments; ${ }^{19}$ the Disability Assessment for Dementia (DAD), modified Instrumental Activities of Daily Living Scale, and Physical SelfMaintenance Scale (PSMS) for functional measures; ${ }^{20,21}$ and the Neuropsychiatric Inventory (NPI) for behaviour. ${ }^{22}$ A variety of other instruments were also used to assess global functioning (the Functional Rating Scale), ${ }^{23}$ caregiver outcomes (Caregiver Stress Scale), ${ }^{24}$ (Health-Related Quality of Life of Caregiver Questionnaire), ${ }^{25}$ and a resource utilization scale (The Canadian Utilization of Services Tracking Questionnaire). ${ }^{26}$ Donepezil therapy was associated with significant benefits on the CIBIC+, as well as both the MMSE and SIB. Because the placebo decline on the SIB was greater than the MMSE, the authors suggested the SIB was more sensitive to change in this population. The other secondary measures including the DAD and NPI also showed statistically significant differences favouring donepezil at endpoint. In their discussion, the authors noted that the $\mathrm{CIBIC}+$ was chosen as the primary outcome measure given questions about the clinical relevance of small but significant changes in cognition at this stage of the illness. They also noted that unlike the floor effects encountered with the MMSE, the SIB demonstrated a 2.1 point improvement with donepezil compared with a 3.6 decline in the placebo group, demonstrating that measurable changes in cognition are possible at this stage of illness, as well as confirming the SIB's usefulness as an outcome measure.

The second study was a 24-week randomized, double-blind, placebo-controlled parallel group trial of donepezil in 208 nursing home residents. ${ }^{27}$ Inclusion criteria included scores of 526 on the MMSE and at least one neuropsychiatric symptom from the NPI, which occurred several times per week. This resulted in a group with average MMSE scores of approximately 14 , with $22-26 \%$ being severe and $60-62 \%$ being moderate. The primary outcome measure was the NPI-NH (nursing home version) with secondary measures, the MMSE, the Clinical Dementia Rating Scale-Sum of Boxes (CDR-SB), ${ }^{28}$ and PSMS. There were no statistically significant differences noted at endpoint on the NPI-NH, MMSE and PSMS, though scores on CDR-SB suggested significant benefit for donepezil therapy. These authors also raise concerns about the sensitivity of the MMSE to detect decline in more seriously impaired patients.

\section{Memantine}

The best studied treatment for moderate to severe AD is the non-competitive NMDA-receptor antagonist memantine. In a brief 12-week randomized, double-blind, placebo- controlled parallel group design, memantine therapy was studied in 166 patients in a psychiatric hospital or in nursing homes. ${ }^{29}$ Inclusion criteria included MMSE $<10$ and Global Deterioration Scale $(G D S)^{30}$ score of 5-7. Average MMSE scores were approximately 6 with over $96 \%$ of patients being staged as either severe or very severe. Fifty-two percent of subjects had high Hachinski Ischemic Scale scores, suggestive of mixed or vascular dementia. Primary outcome measures were the Clinical Global Impression of Change, ${ }^{31}$ and the Behavioral Rating Scale for Geriatric Patients (BGP). ${ }^{32}$ The Ferm's D-test was used as a secondary measure of functioning. ${ }^{33}$ Treatment effects favoured memantine on all measures. In a 28 -week double-blind, placebocontrolled, parallel group trial of memantine, 252 patients with moderate to severe AD were studied by Reisberg et al. ${ }^{34}$ Inclusion criteria included MMSE scores of 3-14 and a GDS of 5 or 6 . This resulted in a study population with an average MMSE score of approximately 8 with $44 \%$ staged as moderate $(\mathrm{GDS}=5)$ and $56 \%$ moderate to severe (GDS=6). Primary outcome measures were the CIBIC+ and Alzheimer's Disease Cooperative Study Activities of Daily Living Inventory modified for more severe dementia (ADCS-ADLSEV). ${ }^{35}$ Secondary measures included the SIB and MMSE for cognition, the GDS and FAST for global staging, the NPI for behaviour, and the Resource Utilization in Dementia scale for health-related economic outcomes. ${ }^{36}$ The ITT-LOCF endpoint analysis of the $\mathrm{CIBIC}+$ demonstrated a trend favouring memantine $(\mathrm{p}=0.06)$ while the observed case analysis statistically favoured memantine ( $\mathrm{p}=0.03$ ). The ADCS-ADLSEV statistically favoured memantine, as did cognitive outcomes with the SIB. In this study, memantine treated patients declined by 4 points on the SIB compared to 10 points in placebo-treated patients $(\mathrm{p}<0.001)$. In contrast, there were no significant differences on the MMSE. Livingston and Katona have recently analyzed these two studies with numbers needed to treat analysis (NNT). ${ }^{37}$ A responder analysis from the Winbald and Poritis study in severe dementia was statistically significant with NNTs of 3 and 4 . Based on the Reisberg et al. study, the NNT for improvement or stabilization in the CIBIC+ and one of the secondary outcome measures (SIB or ADL) was 6 ( $\mathrm{p}=0.004,95 \% \mathrm{CI}: 4-12)$. The numbers needed to harm (NNH) for adverse outcomes were all similar except for agitation, with placebo having a significantly higher risk 
$(\mathrm{NNH}=8)$. Finally, effect sizes from both studies ranged from 0.32-0.62. The authors concluded that given the low NNTs, a medium effect size, and an extremely benign safety profile, memantine appears to have clinically significant benefit in moderate to severe $\mathrm{AD}$ with a magnitude that is similar for ChEIs in mild to moderate disease.

In the third study, Tariot et al examined the use of memantine in 404 moderate to severe $\mathrm{AD}$ patients already treated with donepezil in a randomized, double-blind, placebo-controlled trial of 24 weeks duration. ${ }^{38}$ Inclusion criteria included MMSE 5-14 and donepezil therapy for at least six months prior to randomization. Average baseline MMSE scores were approximately 10 . The primary outcome measures were the SIB and ADCS-ADLSEV. Secondary measures were CIBIC+, NPI, and the BGP. All outcome measures favoured memantine with statistical significance.

\section{Alpha-Tocopherol/Selegiline}

In a two-year double-blind, placebo-controlled parallel group design, Sano et al studied 341 moderate to severe AD patients with alpha-tocopherol (vitamin E), selegiline, or the combination. ${ }^{39}$ Inclusion criteria included a Clinical Dementia Rating (CDR) of 2 (moderate severity), resulting in groups with baseline MMSEs that averaged approximately 11-13. The primary outcome measure was time-to-occurrence of any of death, institutionalization, loss of two to three basic activities of daily living (eating, grooming, using the toilet) as measured by the Blessed Dementia Scale, ${ }^{40}$ or a CDR rating of 3 (severe dementia). Secondary measures included the Alzheimer's Disease Assessment Scale, cognitive subscale (ADAS-cog) and MMSE for cognition, ${ }^{41}$ the Blessed Dementia Scale and Dependence Scale for function, ${ }^{42}$ and the Behaviour Rating Scale for dementia. ${ }^{43}$ Unfortunately, there was a trend towards significant differences among the treatment groups in baseline MMSE scores. There was no difference in the primary outcome for any of the groups but, after adjusting for baseline MMSE, a significant delay in the primary outcome was noted for selegiline, alpha-tocopherol, and the combination. There were no significant differences in the cognitive measures, leading the authors to suggest that other aspects of moderate to severe AD, such as behavior and function, may make it difficult to assess cognition, and cognition may not be the best measure of disease progression at this stage.

\section{COMment/Summary}

There are limited data supporting the use of pharmacological agents to treat moderate to severe AD. Use of donepezil appears promising based on one positive RCT and a second study with a positive secondary global outcome as measured by the CDR-SB. Post-hoc analyses of trials with galantamine and rivastigmine suggest the benefits may be a class effect, though further studies would be helpful. The positive clinical results are supported by neuropathological evidence, suggesting cholinergic markers are appropriate targets at this stage of illness. ${ }^{10}$ Treatment with memantine - an NMDA antagonist - also seems promising based on three RCTs, including a study suggesting combined therapy with donepezil and memantine is better than donepezil alone. Finally, there is some evidence that the antioxidants alpha tocopherol and selegiline may delay the progression of the illness, though significant methodological problems raise concerns about the validity of these results and further confirmatory studies are necessary. ${ }^{44}$ While providing treatment guidelines for moderate to severe AD based on these few studies would be overly ambitious, they do raise important methodological issues for studying moderate to severe AD and can provide guidance for recommendations about appropriate trial designs.

\section{Trial Designs for Moderate to Severe AD}

\section{Inclusion Criteria}

Moderate to severe $\mathrm{AD}$ can be reliably distinguished from milder disease by a combination of global staging and MMSE score. ${ }^{45}$ GDS (and FAST) stages 5 (moderate), 6 (moderate to severe), and 7 (severe) or CDR stages 2 (moderate), 3 (moderate to severe), 4 and 5 (severe) would be appropriate stages and rating instruments for moderate to severe AD studies. The MMSE scores of 10-19 have generally been considered consistent with moderate $\mathrm{AD}$ and $<10$ severe $\mathrm{AD}$. While the studies reviewed previously included a variety of upper limits for the MMSE (usually 10-17), it is recommended that average baseline MMSEs for studies of moderate to severe $\mathrm{AD}$ be no greater than 12 .

\section{Design}

All moderate to severe AD trials should be randomized and double-blind. As mentioned previously, there are currently no CGPs for moderate to severe $\mathrm{AD}$, though CPGs for mild to moderate $\mathrm{AD}$ have generally recommended a trial of a cholinesterase inhibitor. ${ }^{46}$ It is, therefore, reasonable to recommend placebo-controlled trials, especially if the trial focuses on severe AD (GDS 7, CDR 4 or 5, MMSE <10). Trials that utilize an equivalency or non-inferiority design, with the investigational drug compared to cholinesterase inhibitors, are recommended, especially if moderate patients are included. Sample size calculations for these designs may necessitate a need for large sample sizes. ${ }^{47}$ Another recommended design would include all patients being treated with "standard care" (e.g., ChEIs) using a parallel group design comparing the investigational drug to placebo. This design might result in an approved indication for combined therapy only (as opposed to monotherapy). A final design would include a parallel group design with three arms: standard care plus placebo, standard care plus investigational drug, and investigational drug plus placebo.

\section{Outcome Measures}

Outcome measures in moderate to severe AD trials will differ from mild to moderate AD trials because of psychometrics and different stage-specific goals. ${ }^{48}$ Since small changes in cognitive function may have questionable clinical relevance at this stage of $\mathrm{AD}$, it is recommended that primary outcome measures include a global rating and either a functional or behavioural measure. Cognitive, functional, behavioural, and measures of caregiver distress are all appropriate secondary measures. The CIBIC + is one recommended global outcome measure that has been used in previous moderate to severe $\mathrm{AD}$ studies and appears to be sensitive to change. There is some suggestion that this instrument relies more heavily on ADL and behavioural change, 
which would be appropriate for moderate to severe AD trials. ${ }^{45}$ Function can be measured with the ADCS-ADLSEV or DAD, both of which are sensitive to change in this population. Unfortunately, these scales might be limited in long-term care institutions where patients frequently do not have the opportunity to demonstrate functional competence on all the activities of daily living assessed. Behaviour can be measured with the NPI. Cognitive measures such as the MMSE and ADAS-cog are limited by a floor effect, as noted in the previous moderate to severe AD studies. ${ }^{48}$ The SIB has demonstrated excellent sensitivity in this population. The SIB appears to be most useful in patients with MMSE $<10$ and may suffer from a ceiling effect in patients with moderate disease (e.g., MMSE $>15)^{45}$

Stabilization of function, behaviour, and cognition is a reasonable goal of therapy and possibly more realistic than significant improvement at this stage of illness. Pharmacoeconomic outcomes are important and might focus on indirect costs, such as caregiver time, which make up a significant proportion of costs for community dwelling patients. Finally, while health-related quality of life is an important outcome, practical and theoretical issues have limited its measurement and there is no consensus about valid and reliable measures at the present time. This would be particularly problematic for moderate to severe $\mathrm{AD}$ where proxy measures would have questionable validity.

\section{SUMMARY}

In conclusion, moderate to severe AD represents a significant societal health problem with respect to prevalence, symptomatology, caregiver burden, and pharmaco-economics. There are emerging data that the cholinesterase inhibitors and memantine may be useful therapies at this stage of illness, though further studies are necessary. The clinical trials completed to date do provide evidence that there are specific rating instruments and trial designs that are valid and reliable in this patient population.

\section{Disclosure}

Dr. Herrmann has received research support and honoraria from Janssen-Ortho, Pfizer, Novartis, and Lundbeck.

\section{REFERENCES}

1. Canadian Study of Health and Aging Working Group. Patterns of caring for people with dementia in Canada. Can J Aging. 1994;13:470-87.

2. Tariot PN. Medical management of advanced dementia. J Am Geriatr Soc. 2003;51: S305-13.

3. Hux MJ, O'Brien BJ, Iskedjian M, Goeree R, Gagnon M, Gauthier S. Relation between severity of Alzheimer's disease and costs of caring. CMAJ. 1998;159:457-65.

4. Wimo A, Karlsson G, Nordberg A, Winblad B. Treatment of Alzheimer's disease with tacrine: a cost-analysis model. Alzheimer Dis Assoc Disord. 1997;11:191-200.

5. Di Patre PL, Read SL, Cummings JL, Tomiyasu U, Vartavarian LM, Secor DL, et al. Progression of clinical deterioration and pathological changes in patients with Alzheimer's disease evaluated at biopsy and autopsy. Neurology. 1999;56:1254-61.

6. Lanctôt KL, Herrmann N, Mazzotta P. Role of serotonin in the behavioural and psychological symptoms of dementia. J Neuropsychiatry Clin Neurosci. 2001;13:5-21.
7. Herrmann N, Lanctôt KL, Khan LR. The role of norepinephrine in the behavioural and psychological symptoms of dementia. J Neuropsychiatry Clin Neurosci. 2004; 16:261-76.

8. Lanctôt KL, Herrmann, N, Mazzotta P, Khan LR, Ingber N. GABAergic function in Alzheimer's disease: evidence for dysfunction and potential as a therapeutic target for the treatment of behavioural and psychological symptoms of dementia. Can J Psychiatry. 2004;49:439-53.

9. Cacabelos R, Takeda M, Winbald B. The glutamatergic system and neurodegeneration in dementia: preventative strategies in Alzheimer's disease. Int J Geriatr Psychiatry. 1999;14:3-47.

10. Davis KL, Mohs RC, Marin D. Cholinergic markers in elderly patients with early signs of Alzheimer's disease. JAMA. 1999;281:1401-6.

11. Feldman H, Gauthier S, Hecker J, Vellas B, Subbiah P, Whalen E. A 24-week, randomized, double-blind study of donepezil in moderate to severe Alzheimer's disease. Neurology. 2001;57:613-20.

12. Folstein MF, Folstein SE, McHugh PR. Mini-mental state: a practical method for grading the cognitive state of patients for the clinician. J Psychiatr Res. 1975;12:189-98.

13. Herrmann N. Recommendation for the management of behavioural and psychological symptoms of dementia. Can J Neurol Sci. 2001;28(Suppl 1):S96-107.

14. Lanctôt KL, Herrmann N, Yau KK, Khan LR, LouLou MM, Einarson TR. Efficacy and safety of cholinesterase inhibitors in Alzheimer's disease: a meta-analysis. CMAJ. 2003;169:557-64.

15. Blesa R, Davidson M, Kurza A, Reichman W, van Baelen B, Schwalen S. Galantamine provides sustained benefits in patients with advanced moderate Alzheimer's disease for at least 12 months. Dement Geriatr Cogn Disord. 2003;15:79-87.

16. Doraiswany PM, Krishnan KR, Anand R, Sohn H, Danyluk J, Hartman RD, et al. Long-term effects of rivastigmine in moderately severe Alzheimer's disease: does early initiation of therapy offer sustained benefits? Prog Neuropsychopharmacol Biol Psychiatry. 2002;26:705-12.

17. Sclan SG, Reisberg B. Functional assessment staging (FAST) in Alzheimer's disease: reliability, validity, and ordinality. Int Psychogeriatr. 1992;4(Suppl 1):S55-69.

18. Schneider LS, Olin JT, Doody RS, Clark CM, Morris JC, Reisberg $\mathrm{B}$, et al. Validity and reliability of the Alzheimer's disease cooperative study-clinical global impression of change. Alzheimer Dis Assoc Disord. 1997;11(Suppl 2):S22-32.

19. Saxton J, McGonigle-Gibson G, Swihart A, Miller VJ, Boller F. Assessment of the severely impaired patient: description and validation of a new neuropsychological test battery. Psychol Assessment: J Consulting Clin Psychology. 1990;2:298-303.

20. Gelinas I, Gauthier L, McIntyre M, Gauthier S. Development of a functional measure for persons with Alzheimer's disease: the disability assessment for dementia. Am J Occup Ther. 1999;53:471-81.

21. Lawton MP, Brody EM. Assessment of older people: selfmaintaining and instrumental activities of daily living. Gerontologist. 1969;9:179-86.

22. Cummings JL. The neuropsychiatric interview: assessing psychopathology in dementia patients. Neurology. 1994;44: 2308-14.

23. Feldman H, Schulzer M, Wang S, Tuokko H, Beattie BL. The functional rating scale in Alzheimer's disease assessment: a longitudinal study. In: Iqbal K, Mortimer JA, Winbald B, Wisniewski HM, editors. Research advances in Alzheimer's disease and related disorders. Chichester, UK: Wiley; 1995. p. 235-41.

24. Pearlin LI, Mullan JT, Semple SJ, Skaff MM. Caregiving and the stress process: an overview of concepts and their measures. Gerontologist. 1990;30:583-94.

25. McHorney CA, Ware JE. Construction and validation of an alternate form general mental health scale for the medical outcomes study short-form 36-item health survey. Med Care. 1995;33:15-28.

26. Østbye T, Crosse E. Net economic costs of dementia in Canada. CMAJ. 1994;151:1457-64. 
27. Tariot PN, Cummings JL, Katz IR, Mintzer J, Perdomo CA, Schwam EM, et al. A randomized, double-blind, placebo-controlled study of the efficacy and safety of donepezil in patients with Alzheimer's disease in the nursing home setting. J Am Geriatr Soc. 2001;49:1590-9.

28. Morris JC. The clinical dementia rating (CDR): current version and scoring rules. Neurology. 1993;43:2412-14.

29. Winblad B, Poritis N. Memantine in severe dementia: results of the M-Best study (benefits and efficacy in severely demented patients during treatment with memantine). Int $\mathrm{J}$ Geriatr Psychiatry. 1999;14:135-46.

30. Reisberg B, Ferris SH, de Leon MJ, Crook T. The global deterioration scale (GDS): an instrument for the assessment of primary degenerative dementia (PDD). Am J Psychiatry 1982;139:1136-9.

31. National Institute of Mental Health. Clinical Global Impressions. In: Guy W, editor. ECDEU Assessment Manual for Psychopharmacology. National Institute of Mental Health, Rockville, MD. 1986: p.217-22.

32. Van der Kam P, Mol F, Wimmers M. Beoordelingschool voon oudere patienten (BOP). Deventer, the Netherlands: Van Loghum Slaterus; 1971.

33. Ferm L. Behavioural activities in demented geriatric patients. Geront Clin. 1974; 16:185-94.

34. Reisberg B, Doody R, Stoffler A, Schmitt F, Ferris S, Mobius HJ. Memantine in moderate-severe Alzheimer's disease. N Engl J Med. 2003;348:1333-41.

35. Galasko DR, Schmitt FA, Jin S. Detailed assessment of cognition and activities of daily living in moderate to severe Alzheimer's disease. Neurobiol Aging. 2000; 21(suppl 1):S168.

36. Wimo A, Wetterholm AL, Mastey V, Winblad B. Evaluation of the healthcare resource utilization and caregiver time in antidementia drug trials - a quantitative battery. In: Wimo A, Johnsson D, Karlson G, Winblad B, editors. Health economics of dementia. Chichester, England: John Wiley; 1998. p. 465-99.

37. Livingston $\mathrm{G}$, Katona $\mathrm{C}$. The place of memantine in the treatment of Alzheimer's disease: a number needed to treat analysis. Int $\mathrm{J}$ Geriatr Psychiatry. 2004;19:919-25.

38. Tartiot PN, Farlow MR, Grossberg GT, Graham SM, McDonald S, Gergel I. Memantine treatment in patients with moderate to severe Alzheimer's disease already receiving donepezil. JAMA. 2004; 291:317-24.
39. Sano M, Ernesto C, Thomas RG, Klauber MR, Schafer K, Grundman $\mathrm{M}$, et al. A controlled trial of selegiline, alpha-tocopherol on both as treatment for Alzheimer's disease. N Engl J Med. 1997;336: 1216-22.

40. Blessed G, Tomlinson BE, Roth M. The association between quantative measures of dementia and of senile changes in the cerebral grey matter of elderly subjects. $\mathrm{Br} \mathrm{J}$ Psychiatry. 1968;114:797-811.

41. Rosen WG, Mohs, RC, Davis KL. A new rating scale for Alzheimer's disease. Am J Psychiatry. 1984;141:1356-64.

42. Stern Y, Albert SM, Sano M. Assessing patient dependence in Alzheimer's disease. J Gerontol A Biol Sci Med Sci. 1994;49: M216-22.

43. Tariot PN, Mack JL, Patterson MB. The behaviour rating scale for dementia of the consortium to establish a registry for Alzheimer's disease: the behavioural pathology committee of the consortium to establish a registry for Alzheimer's disease. Am J Psychiatry. 1995;152:1349-57.

44. Drachman DA, Leber P. Treatment of Alzheimer's diseasesearching for a breakthrough, settling for less. N Engl J Med. 1997;336:1245-7.

45. Ferris SH, Yan B. Differential diagnosis and clinical assessment of patients with severe Alzheimer's disease. Alzheimer Dis Assoc Disord. 2003;17(Suppl 3):S92-5.

46. Doody RS, Stevens JC, Beck C, Dubinsky RM, Kaye JA, Gwyther L, et al. Practice parameter: management of dementia (an evidence-based review): report of the quality standards subcommittee of the American Academy of Neurology. Neurology. 2001;56:1154-66.

47. Streiner DL. Unicorns do exists: a tutorial on "proving" the null hypothesis. Can J Psychiatry. 2003;48:756-61.

48. Boller F, Verny M, Hugonot-Diener L, Saxton J. Clinical features and assessment of severe dementia: a review. Eur J Neurol. 2002;9:125-36 